
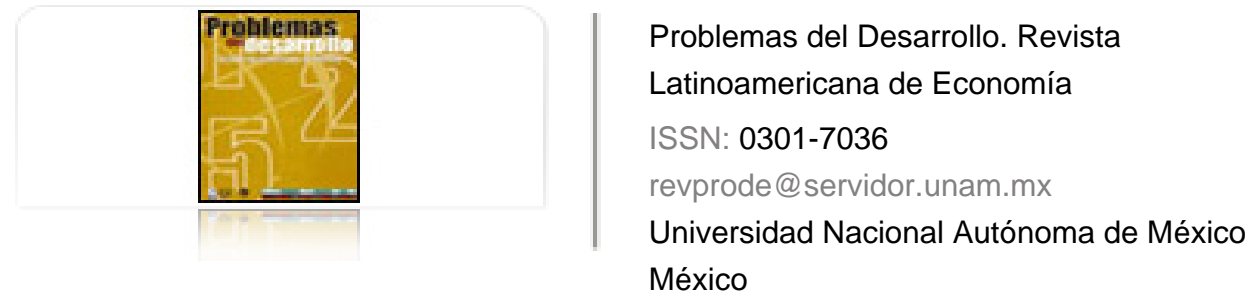

Huerta Moreno, Ma. Guadalupe; Kato Maldonado, Luis

Hacia la construcción de nuevos enfoques sobre globalización y crisis

Problemas del Desarrollo. Revista Latinoamericana de Economía, vol. 42, núm. 164, enero-marzo,

2011, pp. 25-53

Universidad Nacional Autónoma de México

Distrito Federal, México

Disponible en: http://www.redalyc.org/articulo.oa?id=11819774003

- Cómo citar el artículo

- Número completo

- Más información del artículo

Página de la revista en redalyc.org

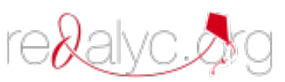

Sistema de Información Científica

Red de Revistas Científicas de América Latina, el Caribe, España y Portugal Proyecto académico sin fines de lucro, desarrollado bajo la iniciativa de acceso abierto 


\title{
HaCia la CONSTRUCCIÓN DE NUEVOS ENFOQUES SOBRE GLOBALIZACIÓN Y CRISIS
}

\author{
Ma. Guadalupe Huerta Moreno* y Luis Kato Maldonado**
}

Fecha de recepción: 1 de octubre de 2010. Fecha de aceptación: 4 de diciembre de 2010.

\section{RESUMEN}

En este artículo se analiza la enorme crisis financiera actual a la luz de conceptos como incertidumbre, renta de la tierra y centralización de capitales. Categorías analíticas que no son relevantes para la economía neoclásica y están presentes en el funcionamiento del sistema financiero ligado a la etapa más reciente de la globalización financiera. En la que se formó una red de intermediación sostenida por innovaciones financieras (en productos y procesos) donde el capital dinerario se canalizó a operaciones especulativas en detrimento del sector real. Al estallar la burbuja especulativa se abrieron nuevos flancos para el debate económico: en el terreno teórico, cuestionando las propuestas previas de análisis y prevención de crisis; respecto del papel del Estado para revertir el estancamiento económico resultante de la crisis y en relación con las políticas que implementará en el sistema financiero.

Palabras clave: Globalización, innovaciones financieras, renta de la tierra, tasa de ganancia.

\section{TOWARDS THE CONSTRUCTION OF NEW FOCUSES ON GLOBALIZATION AND CRISIS}

\section{Summary}

The present article analyzes the current enormous financial crisis in the light of such concepts as uncertainty, land rent and capital centralization, analytical categories that are not relevant to neoclassical economics but which are present in the functioning of the financial system, linked as it is to the latest stage of financial globalization, in what formed an intermediary network based on financial innovation (in products and processes) where money capital was channeled into speculative operations to the detriment of the real sector. When the speculative bubble burst it opened new areas for economic debate: on the theoretical side, questioning the previous proposals for analysis and the prevention of crises; on practical side, regarding the role of the State in reversing the economic stagnation that resulted from the crisis and in relation to what policies should be implemented in the financial system. Key words: Globalization, financial innovations, land rent, profit margin.

* Profesora titular “C” del Departamento de Administración de la UAM-Azcapotzalco. Correo electrónico: mghmoreno@yahoo.com.mx

** Profesor titular “C” del Departamento de Economía de la UAM-Azcapotzalco. Correo electrónico: jarumi@prodigy.net.mx 
Ma. Guadalupe Huerta Moreno y Luis Kato Maldonado

\section{VERS LA CONSTRUCTION DE NOUVEAUX REGARDS SUR MONDIALISATION ET CRISE}

Résumé

Dans cet article, il est fait l'analyse de l'énorme crise financière actuelle à la lumière de concepts comme l'incertitude, la location de la terre et la centralisation de capitaux. Des catégories analytiques qui ne sont pas importantes pour l'économie néoclassique et sont présentes dans le fonctionnement du système financier pendant l'étape la plus récente de la mondialisation financière. Au cours de celle-ci, s'est formé un réseau d'intermédiation soutenu par des innovations financières (en produits et processus) où le capital en valeur a été canalisé vers des opérations spéculatives au détriment du secteur réel. Avec l'explosion de la bulle spéculative se sont ouverts de nouveaux flancs pour le débat économique : sur le terrain théorique, en mettant en question les propositions préalables d'analyse et de prévention de crise ; sur le plan pratique, en ce qui concerne le rôle de l'État pour sortir de la stagnation économique produite par la crise et les politiques qu'il mettra en œuvre dans le système financier. Mots clés : mondialisation, innovations financières, location de la terre, taux de profit

\section{PARA A CONSTRUÇÁO DE NOVOS ENFOQUES SOBRE GLOBALIZAÇÁO E CRISES Resumo}

Neste artigo se analisa a enorme crise financeira atual à luz de conceitos como incerteza, renda da terra e centralização de capitais. As categorias analíticas que não são relevantes para a economia neoclássica estão presentes no funcionamento do sistema financeiro ligado à etapa mais recente da globalização financeira. Neste se formou uma rede de intermediação sustentada por inovaçóes financeiras (em produtos e processos) onde o capital dinerário se canalizou a operaçóes especulativas em detrimento do setor real. Ao explodir a bolha especulativa se abriram novos flancos para o debate econômico: no terreno teórico, questionando as propostas previas de análise e prevenção de crises; no prático, no que condiz ao papel do Estado para reverter o estancamento econômico resultante da crise e em relaçáo com as políticas que se adotarâo no sistema financeiro.

Palavras-chave: Globalização, inovaçóes financeiras, renda da terra, taxa de lucro.

关于全球化以及危机的新视角的形成 摘要

本文分析了当前巨大的金融危机所带来的不确定性，土地租金和资本集 中。这些与古典经济学不相关的新分析范畴是金融全球化的最近阶段的 金融体制运作的特点。形成由金融创新（在产品和流程方面）构成的中 介网，在这一网络中金融资本演变成了投机模式并对实业资本造成了不 良影响。当投机泡沫破灭开辟了新的经济辩论：在理论上，提问了旧的 分析方法和危机预防模式, 在实际操作中, 政府在扭转经济停滞以及 实施新金融政策过程中的作用。

关键词：全球化，金融创新，土地租金，利润率。 


\section{INTRODUCCIÓN}

La arquitectura de la etapa más reciente de la globalización financiera y la regulación financiera diseñada para favorecer la apertura de los mercados de capitales en el mundo tuvieron efectos en la movilidad del capital dinerario a nivel mundial que incidieron de forma determinante en la enorme crisis financiera ${ }^{1}$ que desde 2007 impactó al sistema financiero internacional. Ello introdujo una tensión adicional en el sector real de las economías porque hizo de las esferas financieras el entorno propicio para hacer negocios altamente rentables. En ese contexto hay un elemento nuevo que son las políticas de desarrollo urbano del mercado inmobiliario norteamericano, mismas que se replicaron en los países de la OCDE (Organización para la Cooperación y el Desarrollo Económico). Lo relevante aquí es que la renta de la tierra en los espacios urbanos se convirtió en el eje de inversiones altamente rentables que crearon una enorme burbuja especulativa sostenida por un intrincado arreglo de deudas titularizadas que elevaron la captación de capital dinerario y expandieron el financiamiento en la industria de la construcción. Al estallar la burbuja se abrieron nuevos flancos para un intenso debate económico en los planos teórico y práctico. En el primero, reintroduciendo los conceptos de especulación e incertidumbre, fenómenos ampliamente estudiados por Keynes, como partes esenciales del desequilibrio de las economías capitalistas, ${ }^{2}$ y recuperando de Marx que la libre movilidad del capital mediante la cual se busca alcanzar grandes masas o tasas de ganancia es el motor del proceso de acumulación capitalista, y esa misma movilidad deriva de la posibilidad de que los capitalistas, una vez valorizado su capital en la realización de sus mercancías, no se ven obligados a invertir la misma masa de valor en el siguiente ciclo de producción. Lo que lleva a la crisis generalizada si el capital se mantiene bajo la forma de dinero y no es reinvertido en el proceso de producción. ${ }^{3}$ En el terreno práctico, de la implementación

1 Escogimos al adjetivo enorme porque el Diccionario de la Lengua Española (2000) de la Real Academia Española lo describe como algo “... desmedido, excesivo... perverso", y es eso lo que caracteriza a la actual crisis financiera, su magnitud y diferencias con las crisis de por lo menos las tres décadas previas.

2 Otros grandes economistas que hicieron importantes aportes al estudio de las finanzas son Rudolf Hilferding en relación con el concepto de capital financiero y Michael Kalecki que con la Teoría del Riesgo Creciente enfatizó los efectos del apalancamiento empresarial en el comportamiento agregado de la economía.

3 En consecuencia el monto de capital dinerario que el capitalista podría reinvertir o sacar del proceso de valorización se constituye tanto por el plusvalor que se invertiría (fondo de acumulación) como medios de producción, como por el valor del capital constante fijo recuperado (fondo de depreciación) por la venta de sus mercancías. 
de las políticas, resaltar que en Keynes los potenciales efectos de las crisis financieras en la esfera productiva y la inversión son una de las justificaciones para que el Estado intervenga en la economía a fin de revertir el estancamiento económico y atenuar las ineficiencias del funcionamiento del mercado. Por su parte recuperar de Marx que el Estado tiene un carácter de clase y en este sentido puede ocurrir que su intervención en las esferas monetaria y financiera no sólo propicie la competencia inter e intracapitalista que sustenta procesos de concentración y centralización de capitales sino que los préstamos y las acciones se convierten en herramientas complementarias al servicio de la fracción superior de las clases dominantes y sus instituciones de poder, léase el capital financiero (Duménil, Gérard y Dominique Lévy, 2003).

Contextualizadas esas ideas en la enorme crisis financiera actual nos lleva a la revisión de categorías de análisis que la teoría económica neoclásica no considera relevantes (la incertidumbre, la fragilidad de los sistemas financieros, la concentración del capital y la renta de la tierra, etcétera) que son fundamentales para construir marcos explicativos que incluyan elementos que se desprenden de la observación permanente del funcionamiento, en el caso que nos ocupa, de los mercados financieros.

De esa reflexión se desprende el presente artículo, que tiene por objetivo mostrar, en un primer apartado, cómo a partir de la globalización y la financiarización de la economía se socializaron riesgos que crearon escenarios para la inversión productiva subordinados y, en algunos casos, totalmente desplazados por la ganancia especulativa en las esferas financieras. En el segundo apartado se busca exponer cómo la propiedad de la tierra tuvo un papel esencial en la especulación y el aseguramiento del valor del dinero en los sistemas financieros. Esto es útil para explicar, en el tercer apartado, que las características y la magnitud de la crisis no puede explicarse con las interpretaciones dominantes sobre las crisis previas, y que las políticas que de éstas se desprenden son insuficientes porque no se reconoce en el capitalismo la recuperación para reconocer que la contradicción entre especulación y acumulación de capital sólo puede acometerse con una destrucción masiva del mismo o bien con el estricto control del Estado sobre el funcionamiento de los mercados financieros, y sólo así se podría evitar el estancamiento de largo plazo y la permanencia del desempleo masivo.

\section{LA GLOBALIZACIÓN FINANCIERA, SOCIALIZACIÓN DE RIESGOS, ESPECULACIÓN E INCERTIDUMBRE}

La globalización avanzó en la parte financiera tanto en la innovación de procesos como en productos aceleradamente después del rompimiento de las reglas 
de funcionamiento del sistema financiero internacional heredadas del sistema de Bretton Woods (Eichengreen and Bordo, 2002). ${ }^{4}$ Esto marcó el tránsito entre el funcionamiento de una economía y una estructura financiera internacionales basado en tipos de cambio y tasas de interés fijas y una economía mundial marcada por una creciente integración económica entre países ${ }^{5}$ donde el valor de las operaciones financieras transfronterizas y el libre movimiento de capitales superó al de los intercambios comerciales (Hiernaux-Nicolas, 2002; Puyana, 2005). Con esto aumentaron las tensiones entre los objetivos de crecimiento interno de los países y la dinámica de operaciones financieras que giran en torno de la especulación financiera internacional, característica central, como señala Rozo (2000), "de la acumulación capitalista en el ámbito mundial”. Esta etapa de la globalización financiera, ${ }^{6}$ entendida como tendencia de largo plazo, que se expresa en la creación de redes financieras y una mayor interrelación de las operaciones entre las plazas y los instrumentos financieros de los mercados de los países desarrollados y en desarrollo, pero también en la consolidación de mercados financieros más para intermediarios que para usuarios individuales de los servicios financieros (Allen and Santomero, 1999). De la misma destacaremos por su relevancia:

a) La proliferación de inversionistas institucionales -fondos de pensiones, fondos mutuos, sociedades de inversión y compañías de seguros- en oposición a inversionistas individuales, que se expandieron por las oportunidades de ganancia esperadas del ambiente especulativo propio de la libre movilidad de capitales alrededor del mundo. En palabras de Correa: “...no son un fenómeno nuevo. Sin embargo, su presencia en los mercados financieros ha sido creciente en los últimos años y han pasado a ocupar un lugar preeminente tanto por el volumen de recursos que manejan como por su posición en los mercados, sus estrategias de colección, su diversa vinculación con

4 En este trabajo se expone, en el contexto de la internacionalización de los mercados de capitales previa a 1914 y posterior a 1971, un análisis de las diferentes etapas por las que ha transitado la globalización y se hace una interesante reflexión del tipo de crisis producidas en esos periodos.

5 Aunque la globalización de ninguna manera borró las diferencias estructurales entre países ni ha producido la integración global, en un solo mercado mundial, como a principios de los setentas se pronosticaba.

6 El desarrollo de las tecnologías de información y comunicación también contribuyeron al auge de las operaciones financieras alrededor del mundo desde el último tercio del siglo pasado porque la transmisión de datos en tiempo real posibilitó una más rápida toma de decisiones en la gestión de los portafolios de inversión. 
otros intermediarios financieros, etcétera" (2000:103). Como señalamos en otro lugar (Huerta, 2009), su importancia está en los montos de activos que controlan. Según datos del Banco de Pagos Internacionales (BIS, por sus siglas en inglés) y la OCDE en 1995 los inversionistas institucionales de Estados Unidos, Japón, Reino Unidos, Francia y Alemania contabilizaron activos por 19465 billones de dólares, cifra que en 2005 alcanzaba 35695 billones de dólares. Montos que en carteras de inversión financiera tienen un potencial desestabilizador enorme para el funcionamiento del sistema financiero internacional. ${ }^{7}$

b) La creciente utilización de las innovaciones financieras en las estrategias de administración de riesgos, tampoco de reciente creación como los derivados y la securitización (Gorton and Rosen, 1995). ${ }^{8}$ En los primeros están incluidos los futuros y las opciones. ${ }^{9}$ Las operaciones con futuros operan como "contratos adelantados" y con la volatilidad en el sistema financiero internacional desde el último tercio del siglo xx, empezaron a incluir como activos subyacentes variables o instrumentos financieros: tasas de interés, divisas o índices accionarios. Por su parte, el manejo reciente de las opciones, en la forma de swaps de valores, divisas y créditos, ${ }^{10}$ se dio por la expectativa de que el inversionista tuviera cobertura de los riesgos de tipo de cambio y de tasas de interés y para asegurar flujos de efectivo futuros mediante la transformación de préstamos de tasas flotantes a fijas (o la inversa) en operaciones crediticias. Como menciona Levy (2010) su uso se orientaba a estabilizar los

7 A lo que se puede agregar su incursión no sólo en el financiamiento de infraestructura en proyectos para la conservación del medio ambiente, en el sector energético, la infraestructura hidráulica y la dotación de agua potable sino también en los fondos que incluían paquetes hipotecarios.

8 Hace 15 años estos autores hicieron un excelente análisis de las ventajas del uso de los derivados como instrumentos para la transferencia y cobertura de riesgos, pero al mismo tiempo señalaban los problemas que podían surgir por su complejidad y tamaño, así como del riesgo de colapso que para el sistema bancario significaba su tenencia por parte de un reducido número de grandes bancos. Conforme su uso se popularizó ese peligro creció exponencialmente.

9 Éstos pueden ser futuros sobre divisas, futuros sobre préstamos u opciones sobre tipos de cambio, por mencionar algunas clases. Rubro que incluye los swaps, contratos establecidos entre dos partes que se comprometen a intercambiar flujos financieros (pago de intereses en moneda nacional o extranjera) vinculados a una obligación adquirida con anterioridad y deberán cubrirse en un plazo futuro).

10 Incluyen valores en la forma de títulos de deuda soberana, divisas o bien el aseguramiento de operaciones crediticias. 
costos y las ganancias en los mercados financieros, sin embargo, se descuidó el potencial desestabilizador que tendrían frente a una contracción de la liquidez en la estructura de apalancamiento que los sostenía.

Por su parte, con la securitización (o titularización), procedimiento financiero de convertir grandes préstamos en paquetes de valores de deuda comerciables suficientemente pequeños -con liquidez, maduración y riesgo específicos-, las deudas titularizadas se volvieron atractivas para bancos de inversión, bancos comerciales medianos e inversionistas institucionales e individuales. ${ }^{11}$

c) Los cambios en la regulación financiera (Demirgüc-Kunt, 2003) y partiendo de la idea de Minsky $(1982,1986)$ de que el sistema financiero es inherentemente inestable y propagador de las crisis, como menciona Clavijo (2001) para mejorar su funcionamiento se requiere algún grado de regulación, misma que se ha diseńado en diversos momentos y para enfrentar diferentes problemas, diferenciando estructura y comportamiento en mercados, instituciones e instrumentos financieros. ${ }^{12}$ En general con la regulación se pretende contener sucesos que son disparadores de riesgos financieros con efectos sistémicos que llevan a fallas económicas o institucionales con pérdidas significativas, incremento en los costos de capital o la reducción de su disponibilidad. ${ }^{13}$

A pesar de lo anterior, han predominado ideas respecto de que asegurar la eficiencia y la estabilidad de los mercados financieros sólo requiere la profundización de su desarrollo (Williamson, 1990)..$^{14}$ Es decir, disciplina del mercado e información estandarizada son suficientes para que los participantes en las actividades financieras (inversionistas, intermediarios, usuarios de servicios

11 En general son instrumentos financieros del largo plazo (títulos o bonos).

12 Existe una extensa literatura al respecto entre la que se puede consultar Freixas y Rochet (1997), así como Schwarcz (2008).

13 Hasta hace muy poco la regulación se centraba en prevenir problemas en los bancos, por ello se buscó imponer restricciones a la composición de las carteras, limitar el riesgo de crédito, establecer reservas y coeficientes de capital, pero dada la naturaleza actual de los riesgos financieros generados por el gran movimiento de capitales, ésta se ha ido orientando a adaptar el concepto de riesgo de crédito a la securitización de activos bancarios, a los riesgos operativos y de tasas de interés (BIS, 1988, 2004).

14 Las políticas específicamente dirigidas al campo financiero son, en línea del Consenso de Washington: la liberalización de las tasas de interés, tipos de cambio competitivos, y la desregulación en la forma de la eliminación de las barreras a la entrada y la salida de capitales. 
financieros) estén conscientes, con una visión ética ${ }^{15}$ "de que tienen la posibilidad de obtener tanto pérdidas como ganancias" (Eichengreen, 2009). Esta perspectiva condujo a los procesos liberalización y desregulación financieras de las denominadas reformas de primera generación y que no toman en cuenta que en un capitalismo financiarizado lo predominante son conductas especulativas que no tienen nada que ver con una racionalidad guiada por la búsqueda de ganancias en la esfera de la producción. Hecho que para Keynes era claro y que lo llevó a afirmar que: "Los especuladores pueden no hacer daño cuando son sólo burbujas en una corriente firme de espíritu de empresa; pero la situación es seria cuando la empresa se convierte en una burbuja dentro de una vorágine de especulación. Cuando el desarrollo del capital en un país se convierte en subproducto de las actividades propias de un casino...” (1981:145). Situación común en la historia reciente de los mercados financieros y sus crisis, que resultaron en las reformas, de segunda generación, ${ }^{16}$ orientadas a crear una institucionalidad acorde con la salvaguarda de los derechos de propiedad del capital.

Ahora bien, la enorme crisis financiera actual, ${ }^{17}$ mostró que la regulación estuvo en desventaja porque la compleja imbricación de innovaciones financieras creó un escenario de apuestas con derivados, que en su forma tangible son "sólo piezas de papel que pueden ser multiplicadas y emitidas en relación con otros tantos instrumentos derivados" (Bellofiore and Halevi, 2009: 4). Muestra de ello es que el abundante capital que empezó a moverse en el mercado financiero internacional desde finales de los años noventa produjo un "boom" en la utilización de ese tipo de instrumentos que acumularon valores nocionales en billones de dólares en contratos sobre divisas (Forwards and Forex Swaps y Currency Swaps), swaps sobre tasas de interés (Interest Rate Swaps) y, especialmente, swaps de incumplimiento crediticios (Credit Default Swaps) que se incluyeron en las carteras de inversión de los más diversos actores dentro y fuera del sector financiero como apuestas especulativas sobre ingresos futuros que no estaban respaldados por activos con altos valores de mercado y tampoco tenían relación con actividad productiva alguna, eran papeles sin ningún valor (Cuadro 1).

15 Cualquiera que sea el significado de la "ética" en los negocios.

16 En materia financiera se concentraron en mejorar la calidad institucional, hacer efectivo el imperio de la Ley, la transparencia, la rendición de cuentas y la imposición de estándares contables a los diferentes intermediarios financieros.

17 Como se mostrará más adelante junto a las innovaciones financieras otro factor determinante de la misma fueron las políticas urbanas del uso del suelo. 
Cuadro 1. Cantidades existentes de Derivados en Mercados Informales (Over-the-Counter).

(Billones de dólares).

\begin{tabular}{|c|c|c|c|c|c|}
\hline \multicolumn{6}{|c|}{ Cantidades Nocionales Existentes } \\
\hline $\begin{array}{c}\text { Por categoría de riesgo } \\
\text { e instrumentos. }\end{array}$ & $\begin{array}{c}\text { Junio } \\
\text { de } 2007\end{array}$ & $\begin{array}{l}\text { Diciembre } \\
\text { de } 2007\end{array}$ & $\begin{array}{c}\text { Junio } \\
\text { de } 2008\end{array}$ & $\begin{array}{l}\text { Diciembre } \\
\text { de } 2008\end{array}$ & $\begin{array}{l}\text { Junio } \\
\text { de } 2009\end{array}$ \\
\hline Total de contratos & 516407 & 595738 & 683814 & 547371 & 604622 \\
\hline $\begin{array}{l}\text { Contratos sobre divisas } \\
\text { (Futuros y Forex) }\end{array}$ & 24530 & 29144 & 31966 & 21266 & 23107 \\
\hline Swpas sobre divisas & 12312 & 14347 & 16307 & 13322 & 15072 \\
\hline Swaps sobre tasas de interés & 272216 & 309588 & 356772 & 309760 & 341886 \\
\hline $\begin{array}{l}\text { Swaps de incumplimiento } \\
\text { crediticio }\end{array}$ & 42581 & 58244 & 57403 & 41883 & 36046 \\
\hline $\begin{array}{l}\text { Resto de instrumentos } \\
\text { derivados }\end{array}$ & 164768 & 188415 & 221366 & 161140 & 188511 \\
\hline
\end{tabular}

Fuente: Elaboración propia con base en BIS, Quarterly Review, December 2009.

De los riesgos en el uso de estos instrumentos destacaremos sólo dos: Primero, las instituciones monetarias incrementaron sus riesgos sin tener que elevar su capital o sus reservas, y lo hicieron porque se negocian de forma bilateral con base en el pago de comisiones dentro de lo que se conoce como Offbalance-sheets (Operaciones fuera de Balance). Segundo, las bolsas de deuda colateralizada (Collateralizad Debt Obligations o CDO's) ${ }^{18}$ o paquetes de valores con respaldo hipotecario (Mortange Backed Securities o MBs) se vendieron a distintos inversionistas (bancos de inversión, bancos comerciales medianos e inversionistas individuales y colectivos en los mercados secundarios) mediante los procesos de titularización. Al financiamiento obtenido por este medio se le conoce como Credit securitization (bursatilización de créditos) o bien Assetbacked financing (financiamiento respaldado con activos) que se utilizó en la cobertura de los créditos hipotecarios. En este rubro se ubican los Swaps de

18 Pueden ser paquetes de deuda de tarjetas de crédito, créditos automotrices, deuda corporativa o soberana y créditos hipotecarios. 
Incumplimiento Creditico (CDS, por sus siglas en inglés). El riesgo radica en que un comprador adquiere paquetes de inversiones en la forma de CDO's y los asegura con la adquisición de un CDs, y el vendedor no está obligado a constituir reservas o algún tipo de garantía para el comprador, incluso puede al mismo tiempo actuar como inversionista al asegurar la operación con otra entidad financiera, un banco de inversión, una aseguradora o una reaseguradora. El soporte de la operación es el valor de mercado de los colaterales de los paquetes de títulos, y de ello pasa a depender no sólo la calidad de la institución financiera sino la solvencia y liquidez de todos los participantes en la operación. La red de obligaciones creada se sostiene por la liquidez y la confianza de los participantes en el mercado financiero, y si ellas cambian por el incremento de la razón de endeudamiento/activos o bien por variaciones abruptas en las tasas de interés o los tipos de cambio que afectan las posiciones financieras de las empresas dentro y fuera del sector financiero, la confianza se deteriora y la incertidumbre se generaliza. Para Keynes esto se traduciría en un pesimismo respecto del futuro de los negocios, que llevado a las circunstancias actuales, haría imposible colocar nuevos paquetes de deuda en el mercado y el refinanciamiento de los viejos paquetes de deuda se paraliza. $\mathrm{Al}$ romperse la red de pagos sobreviene una crisis de liquidez que al diseminarse entre intermediarios, plazas e instrumentos se convierte en una crisis de insolvencia con efectos sistémicos.

\section{RENTA DE LA TIERRA, RENTA CAPITALIZADA, CENTRALIZACIÓN DEL CAPITAL Y SALVAGUARDA DEL CAPITAL DINERARIO PARA EL MERCADO FINANCIERO}

La creatividad de las instituciones financieras neoliberales parece sin límites. En cuanto el capital dinerario está al alcance de la mano el capital financiero implementa nuevos procedimientos para bursatilizarlo, y trasladar una gran parte de los riesgos a otros agentes. El capital financiero promovió el crecimiento de la economía estadounidense mediante créditos para el consumo de los hogares de ingresos medios, un consumo desbocado de los más ricos y una extensión sin precedentes del crédito hipotecario no sólo a los sectores de altos ingresos sino especialmente a capas de la población de bajos ingresos. La estrepitosa caída del mercado hipotecario llevó al acuerdo de que la burbuja inmobiliaria en Estados Unidos era la causa inmediata de la crisis financiera más grave desde la Gran Depresión. Crisis que se propagó rápidamente a otras partes del mundo dado el enorme tamaño de la economía estadounidense que atraía capital dinerario de todo el mundo y lo colocaba en el mercado inmobiliario. 
Su dinámica se enmarca en un proceso de acumulación de excedentes bajo la forma de capital dinerario que se invirtió en el sector inmobiliario porque en la fase actual del capitalismo financiarizado el eje de acumulación y la ganancia capitalista se desplazó de las actividades generadoras de riqueza productiva a las burbujas especulativas que para sostenerse requieren de más y más capital dinerario. Por ello, la acumulación de liquidez se canalizó desde el sistema financiero al sector inmobiliario, hecho facilitado y potenciado, como ya se comentó, por las innovaciones financieras y los mercados laxamente regulados. Entre 1990 y 1992 se observó un cambio radical en el mercado de créditos hipotecarios que se titularizaron mediante los MBss (Mortange-Backed Securities) y los RMBss (Residencial Mortange-Backed Securities). Con la titularización, los bancos socializaban el monto de capital prestado en la búsqueda de minimizar el potencial riesgo de la insolvencia de los deudores de hipotecas, reduciendo los gastos de los contratos y logrando con ello canalizar recursos financieros para el financiamiento del mercado inmobiliario. Para los inversores, con las acciones vinculadas a las hipotecas diversificaban sus carteras, obtenían pagos de rendimientos superiores ya que las tasas de interés que se pactaban en el crédito hipotecario eran superiores a las tasas de interés bancarias vigentes en ese momento aun descontados los gastos bancarios de la titularización, los costos administrativos de las mBss y los costos de clasificación del riesgo (Gontijo y Oliveira, 2009). La crisis internacional comenzó en un segmento relativamente pequeño del mercado inmobiliario de los Estados Unidos, el mercado de los préstamos hipotecarios de alto riesgo (el mercado subprime), ${ }^{19}$ que representaba alrededor del $4 \%$ de los activos financieros totales de ese país (Daniel Titelman, Esteban PérezCaldentey y Ramón Pineda, 2009). Sin embargo, la crisis no quedó circunscrita sólo a ese mercado ya que la red de intermediarios creada incluyó en el sector financiero por lo menos a bancos de inversión e instituciones hipotecarias, fondos de inversión, aseguradoras y demás inversionistas institucionales, así como

19 Un crédito subprime es aquella hipoteca considerada de "riesgo", pues generalmente se asigna a personas que no cumplen con los requisitos que normalmente los bancos imponen para otorgar préstamos, bien porque no tiene un trabajo estable, porque sus ingresos no son recurrentes o porque no se pueden demostrar con nóminas o recibos los ingresos percibidos, etcétera. Los préstamos subprime tienden a tener una tasa de interés más alta que la tasa de interés preferencial que ofrece a los préstamos tradicionales. Los puntos porcentuales adicionales de interés a menudo se traducen a decenas de miles de dólares en pagos de intereses adicionales sobre la vida de un préstamo a largo plazo. 
a empresas calificadoras; ${ }^{20}$ en el sector real no sólo a la industria de la construcción sino a todas las empresas no financieras tenedoras de inversiones en índices accionarios de los propios intermediarios financieros que arrastró a las bolsas de valores alrededor del mundo. Con ello, los efectos de la crisis se dejaron sentir en los sectores reales y financieros de prácticamente todo el mundo y conforme ésta se iba desenvolviendo las pérdidas iniciales rápidamente se abultaron contrayendo la liquidez internacional. Así, la crisis del mercado inmobiliario se expresó de forma abierta en abril del 2008; en ese momento el índice de precios de casas S\&P/Case-Shiller, había caído un 44\% desde su pico en 2005 (Gráfica I).

Gráfica I. S\&S/Case-Shiller Home Price Îndices

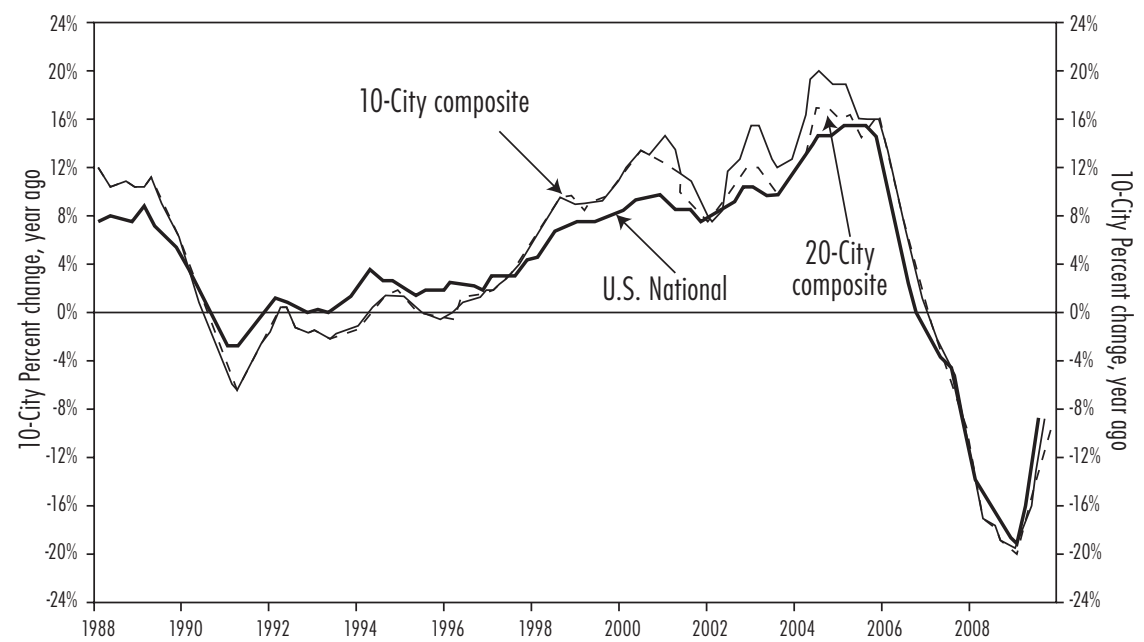

Fuente: Standard \& Poor's. Press release. New York. Noviembre 24, 2009.

Esto es explicado por Astarita en los siguientes términos:

20 Aquí hay que recordar, por una parte, que las calificadoras Moody's, Fitch Ratings y Standard and Poor's eran contratadas y pagadas por los vendedores (bancos o fondos de inversión) para colocar paquetes de inversión que incluían las deudas colateralizadas y, por otra, que las mismas calificaban con los más altos ratings tales inversiones (AAA O AA) para crear las expectativas de ganancia que los hicieran atractivos a los diferentes inversionistas. Es decir, creaban un ambiente en el que parecía que el potencial de pago era seguro y el riesgo de incumplimiento mínimo. 
El 11 de julio quebró IndyMac Bank, un banco especializado en hipotecas con activos por us\$32.000 millones, y altamente comprometido en préstamos hipotecarios conocidos como Alt-A, un tipo de hipotecas entre las subprime y las prime. En este marco, las acciones de Fannie Mae y Freddie Mac se desplomaron. Entre finales de mayo y mediados de julio del 2007 la acción de Fannie Mae cayó el 74\% y la de Freddie Mac el 79\%. Muchos bancos regionales sufrieron grandes pérdidas. Enfrentado a esta situación, y para asegurar que las empresas no se quedaran sin capital, el gobierno se comprometió a adquirir hasta us\$100.000 millones en acciones de cada una. Entre el 25 de julio y el $1^{\circ}$ de agosto caen otros tres bancos, el First National de Nevada, el First Heritage y el First Priority (Astarita, Rolando, 2008: 11)

Este hecho generó diversas inquietudes respecto del funcionamiento del mercado inmobiliario y del funcionamiento del sistema financiero en su conjunto. En primer lugar, los préstamos subprime indujeron el incremento de la demanda de vivienda de los sectores de bajos ingresos, demanda que, sin embargo, condujo a resultados muy heterogéneos en diferentes áreas metropolitanas, dependiendo en gran parte de la regulación del uso del suelo. En algunos mercados metropolitanos, las restricciones de uso de la tierra impulsaron los precios al alza. Por otro lado, en donde la regulación de la tierra no fue tan severa, sólo hubo aumentos modestos de los precios de la vivienda familiar (Cox Wendel, 2009: 2).

Cox señala que Krugman explicaba que la burbuja inmobiliaria de Estados Unidos se concentró en las zonas con fuerte regulación del uso del suelo donde se establecieron políticas de crecimiento urbano controlado tales como: "crecimiento inteligente", "consolidación urbana", o "ciudad compacta".

Entre las 50 áreas metropolitanas con más de 1.000.000 de habitantes, 25 tienen restricciones de utilización de las tierras y 25 están reguladas de manera más laxa. Este tipo de mercados de vivienda estuvieron en condiciones de absorber el excedente de los préstamos bajo la forma de hipotecas (Cox Wendel, 2009: ibidem).

Idea que se confirma en los Cuadros 2 y 3, que muestran cómo las zonas de mayor crecimiento en los precios de las viviendas desde 1991 son las zonas que presentan mayor decremento del precio entre 2009 y 2008. Son estas mismas zonas en donde la restricción por el uso del suelo es mayor y el incremento de precios de las viviendas fue superior durante el auge de la construcción de viviendas en Estados Unidos. 
Ma. Guadalupe Huerta Moreno y Luis Kato Maldonado

Cuadro 2. Cambios de precio de vivienda medido a través de los índices de precios de compra para las 25 áreas metropolitanas por tamaño de población.

Septiembre 30, 2009

Primer trimestre 1991 $=100$

Datos con Ajuste Estacional

\begin{tabular}{|c|c|c|c|c|}
\hline Estadísticas metropolitanas Área o División & Un año & Un trimestre & 5 años & $\begin{array}{c}\text { Desde } 1991 \\
\text { (primer trimestre) }\end{array}$ \\
\hline New York-White Plain-Wayne, NY-NJ (MSAD) & $-5.80 \%$ & $-1.85 \%$ & $6.32 \%$ & $149.77 \%$ \\
\hline Los Angeles-Long Bech-Glendale, CA (MSAD) & $-6.42 \%$ & $-3.79 \%$ & $-12.46 \%$ & $79.58 \%$ \\
\hline Chicago-Naperville-Joliet, IL (MSAD) & $-6.69 \%$ & $2.08 \%$ & $-1.12 \%$ & $98.7 \%$ \\
\hline Houston-Sugar Land-Baytown, TX & $1.25 \%$ & $0.89 \%$ & $22.18 \%$ & $102.32 \%$ \\
\hline Atlanta-Sandy Springs-Marietta, GA & $-5.12 \%$ & $3.65 \%$ & $-4.05 \%$ & $70.73 \%$ \\
\hline $\begin{array}{l}\text { Washington-Arlington-Alexandria,DC-VA-MD-WV } \\
\text { (MSAD) }\end{array}$ & $-0.27 \%$ & $2.71 \%$ & $-2.09 \%$ & $117.43 \%$ \\
\hline Phoenix-Mesa-Scottsdale, AZ & $-22 \%$ & $-2.05 \%$ & $-11.64 \%$ & $94.03 \%$ \\
\hline Riverside-San Bernardino-Ontario, CA & $-16.07 \%$ & $1.05 \%$ & $-36.4 \%$ & $32.48 \%$ \\
\hline Dallas-Plano-Irving, TX (MSAD) & $-0.31 \%$ & $1.49 \%$ & $11.88 \%$ & $72.85 \%$ \\
\hline Philadelphia, PA (MSAD) & $-4.03 \%$ & $-1.33 \%$ & $14.86 \%$ & $112.17 \%$ \\
\hline Minneapolis-St. Paul-Bloomington, MN-WI & $-6.46 \%$ & $0.39 \%$ & $-12.93 \%$ & $114.27 \%$ \\
\hline Santa Ana-Anaheim-Irvine, CA (MSAD) & $-3.34 \%$ & $1.24 \%$ & $-13.34 \%$ & $104.81 \%$ \\
\hline San Diego-Carlsbad-San Marcos, CA & $-4.53 \%$ & $1.56 \%$ & $-26.97 \%$ & $94.52 \%$ \\
\hline St. Louis, MO-IL & $-2.35 \%$ & $-0.94 \%$ & $3.51 \%$ & $96.56 \%$ \\
\hline Nassau-Suffolk, NY (MSAD) & $-4.34 \%$ & $0.99 \%$ & $2.17 \%$ & $137 \%$ \\
\hline Tampa-St. Petersburg-Clearwater, FL & $-12.01 \%$ & $-2.13 \%$ & $-9.74 \%$ & $101.92 \%$ \\
\hline Baltimore-Towson, MD & $-4.82 \%$ & $1.36 \%$ & $14.21 \%$ & $135.94 \%$ \\
\hline Warren-Troy-Farmington Hills, MI (MSAD) & $-14.54 \%$ & $-2.69 \%$ & $-37.78 \%$ & $27.14 \%$ \\
\hline Seattle-Bellevue-Everett, WA (MSAD) & $-11.86 \%$ & $-2.96 \%$ & $17.6 \%$ & $147.12 \%$ \\
\hline Oakland-Fremont-Hayward, CA (MSAD) & $-6.22 \%$ & $3.19 \%$ & $-32.03 \%$ & $71.85 \%$ \\
\hline Denver-Aurora-Broomfield, CO & $3.35 \%$ & $1.11 \%$ & $4.62 \%$ & $175.58 \%$ \\
\hline Pittsburgh, PA & $2.28 \%$ & $1.72 \%$ & $13.08 \%$ & $85.5 \%$ \\
\hline Edison-New Brunswick, NJ (MSAD) & $-4.57 \%$ & $-1.19 \%$ & $4.34 \%$ & $140.05 \%$ \\
\hline Cleveland-Elyria-Mentor, $\mathrm{OH}$ & $-0.41 \%$ & $3.02 \%$ & $-9.78 \%$ & $54.34 \%$ \\
\hline Miami-Miami Beach-Kendall, FL (MSAD) & $-16.18 \%$ & $3.73 \%$ & $-9.77 \%$ & $146.51 \%$ \\
\hline
\end{tabular}

Fuente. Federal Housing Finance Agency, noviembre 24, 2009. 
Algo que se tiene que enfatizar es que el crecimiento del precio de la vivienda desde 2002 al 2006 no fue exclusivo de Estados Unidos. Desde la década de 1970 los precios de la vivienda en términos reales en los países miembros de la OCDE han aumentando en un 3\% promedio anual (Cuadro 3).

\section{Cuadro 3}

Precios de las casas en países desarrollados

Tasa de crecimiento promedio anual

\begin{tabular}{|c|c|c|c|c|c|c|c|}
\hline & 1970-1975 & 1975-1980 & 1980-1985 & $1985-1990$ & 1990-1995 & $1995-2000$ & $2000-2005$ \\
\hline $\begin{array}{l}\text { Estados } \\
\text { Unidos de } \\
\text { Norteamérica }\end{array}$ & $1.6 \%$ & $1.4 \%$ & $1.2 \%$ & $1.1 \%$ & $-1.1 \%$ & $2.3 \%$ & $6.4 \%$ \\
\hline Japón & $3.0 \%$ & $2.1 \%$ & $1.2 \%$ & $0.5 \%$ & $-2.9 \%$ & $-2.6 \%$ & $-4.6 \%$ \\
\hline Alemania & $0.5 \%$ & $0.0 \%$ & $-0.4 \%$ & $-0.7 \%$ & $0.8 \%$ & $-1.6 \%$ & $-2.8 \%$ \\
\hline Francia & $1.8 \%$ & $2.2 \%$ & $2.7 \%$ & $3.2 \%$ & $-2.7 \%$ & $2.1 \%$ & $9.4 \%$ \\
\hline Italia & $6.4 \%$ & $6.4 \%$ & $6.6 \%$ & $7.1 \%$ & $-1.8 \%$ & $-0.9 \%$ & $6.6 \%$ \\
\hline Reino Unido & $5.0 \%$ & $4.4 \%$ & $4.0 \%$ & $3.7 \%$ & $-4.4 \%$ & $8.1 \%$ & $9.9 \%$ \\
\hline Canadá & $6.6 \%$ & $6.8 \%$ & $6.8 \%$ & $6.9 \%$ & $-1.0 \%$ & $0.0 \%$ & $5.9 \%$ \\
\hline Australia & $4.6 \%$ & $4.3 \%$ & $4.0 \%$ & $3.6 \%$ & $-0.2 \%$ & $3.5 \%$ & $7.7 \%$ \\
\hline Dinamarca & $3.9 \%$ & $4.0 \%$ & $3.8 \%$ & $3.4 \%$ & $1.8 \%$ & $6.7 \%$ & $5.5 \%$ \\
\hline Finlandia & $0.9 \%$ & $0.4 \%$ & $0.2 \%$ & $0.0 \%$ & $-10.2 \%$ & $7.8 \%$ & $3.8 \%$ \\
\hline Irlanda & $1.3 \%$ & $1.2 \%$ & $1.0 \%$ & $0.7 \%$ & $1.0 \%$ & $17.6 \%$ & $7.8 \%$ \\
\hline Países Bajos & $3.0 \%$ & $3.4 \%$ & $4.0 \%$ & $4.9 \%$ & $4.6 \%$ & $10.8 \%$ & $2.6 \%$ \\
\hline $\begin{array}{l}\text { Nueva } \\
\text { Zelandia }\end{array}$ & $8.4 \%$ & $7.8 \%$ & $7.3 \%$ & $6.9 \%$ & $2.8 \%$ & $1.7 \%$ & $9.8 \%$ \\
\hline Noruega & $0.5 \%$ & $0.4 \%$ & $0.6 \%$ & $0.7 \%$ & $-0.6 \%$ & $9.3 \%$ & $4.5 \%$ \\
\hline España & $3.8 \%$ & $2.5 \%$ & $2.4 \%$ & $2.5 \%$ & $-1.6 \%$ & $2.6 \%$ & $12.2 \%$ \\
\hline Suecia & $1.2 \%$ & $1.7 \%$ & $2.0 \%$ & $2.5 \%$ & $-5.8 \%$ & $6.3 \%$ & $6.0 \%$ \\
\hline Suiza & $0.8 \%$ & $0.0 \%$ & $-0.6 \%$ & $-1.3 \%$ & $-6.0 \%$ & $-2.7 \%$ & $1.5 \%$ \\
\hline Promedio & $3.1 \%$ & $2.9 \%$ & $2.8 \%$ & $2.7 \%$ & $-1.6 \%$ & $4.2 \%$ & $5.4 \%$ \\
\hline $\begin{array}{l}\text { Promedio } \\
\text { Excluyendo } \\
\text { Alemania y } \\
\text { Japón }\end{array}$ & $3.3 \%$ & $3.1 \%$ & $3.1 \%$ & $3.1 \%$ & $-1.7 \%$ & $5.0 \%$ & $6.6 \%$ \\
\hline
\end{tabular}

Fuente: Nathalie Girouard, Mike Kennedy, Paul van den Noord and Christophe Andre: Recent House Price Developments: theRole o Fundamentals tomado de Paul van den Noord (2006). 
Los datos revelan que la renta de la tierra urbana representó un costo y un ingreso importante para las economías norteamericana y mundial e influyó de forma importante sobre las políticas locales en otros países. La regulación del uso del suelo urbano se efectúa a través del mecanismo de la renta urbana, misma que se refleja en el precio de la tierra o de inmuebles. Como el suelo urbano es un recurso no renovable, sirve como objeto para mantener valor y por ende es un objeto de especulación. Esta característica explica el comportamiento cíclico del sector de la construcción, ya que éste está directamente ligado al uso del suelo y a los movimientos especulativos del precio de la tierra. La renta representa el pago a los propietarios de los recursos naturales no producidos en forma capitalista pero inserta en los procesos de una economía de mercado. En el contexto urbano la renta diferencial y la renta de monopolio juegan un rol clave. La primera es importante para el sector de la construcción y para la estructura espacial de la economía, la segunda tiene efectos centrales sobre la estructura social en el espacio geográfico. La renta diferencial representa la base del precio del terreno en diferentes ubicaciones urbanas: esta renta es el resultado de la ganancia extraordinaria (o diferencial) que pueden lograr los diferentes sectores económicos o grupos de empresas por estar ubicados en cierto lugar favorable, por ejemplo, cercanos a modernas rutas de comunicación, con regulación para el control de emisión de gases, alejadas de las zonas industriales, etcétera. De ahí que la renta diferencial provoca que en una misma área urbana específica solamente se desarrollen actividades económicas con altos niveles de ganancia extraordinaria. Entonces, la renta diferencial intensiva existe debido a la aplicación adicional de capital por unidad de terreno, expresándose lo anterior mediante el aumento de la densidad de metros cuadrados construidos por metro cuadrado de terreno y/o en la remodelación y readaptación de edificaciones ya construidas. La renta de monopolio definida como el precio que se tiene que pagar por un terreno o una vivienda y que no puede ser reproducible por sus condiciones excepcionales de ubicación es el mecanismo central para la estructuración del espacio social y la segregación urbana (Marx, Karl, 1981).

Según su capacidad de pago, los grupos sociales se pueden diferenciar de otros viviendo en un área más cara. En un estudio reciente (Chihiro Shimizu and Tsutomu Watanabe, 2009) se demuestra que la renta es una variable importante que sirve como un nodo entre los precios de los activos y los precios de bienes y servicios, y es necesario aumentar la precisión con que se mide. $\mathrm{Al}$ respecto se señala:

Cuando se analiza la relación entre la demanda de vivienda y precios de la vivienda sobre la base de datos de series temporales en los Estados Unidos de Norteamérica y 
en Japón se encuentra una correlación positiva entre los dos. Sin embargo, al realizar un análisis usando datos por estados o regiones, no existe una relación significativa entre la demanda de vivienda y precios de la vivienda en ambos países. En este sentido, no es posible explicar la existencia de procesos de especulación inmobiliaria a nivel regional a partir del comportamiento de la demanda por vivienda (2009:1).

Consecuentemente, en Estados Unidos se pensaba que los precios de las casas nunca bajarían, con lo cual la renta obtenida y expresada como pago de interés de hipotecas (renta capitalizada) a largo plazo siempre sería superior a la tasa de interés bancaria. De esta manera el crecimiento del sector inmobiliario fue promovido por el gobierno americano que garantizó en un inicio tasas de interés muy bajas a los créditos hipotecarios. Sin embargo, el precio de las propiedades comenzó a bajar debido a:

a) El aumento de la tasa de interés, con lo cual la renta capitalizada expresada como una tasa de renta fue menor a la tasa de interés, Van den Noord (2006: 7).

b) Los grandes flujos de inversión hacia el sector construcción hicieron que la renta diferencial intensiva entre diversas viviendas disminuyera provocando un proceso de eliminación de ganancias extraordinarias. Por lo que con el aumento de la tasa de interés muchos propietarios quisieron vender sus casas provocando una sobreoferta de viviendas. Ésta hizo que los diferenciales de los precios de las casas se redujeran haciendo que las nuevas construcciones tuvieran las mismas características que las primeras construidas, pero a un menor precio y ubicadas en las mismas zonas (renta diferencial intensiva). El efecto fue una baja generalizada del precio de las casas y disminución de la renta capitalizada. Al mismo tiempo, cuando las tasas de interés subieron se redujo aún más el precio de las propiedades inmobiliarias y los intereses que se cobraban por éstas no correspondían ya al precio de las propiedades, generando con ello insolvencia en primer lugar para los deudores de las propiedades y posteriormente para todo el sistema financiero que había titularizado las hipotecas. El excedente económico canalizado al sector inmobiliario de repente desapareció como activo y, a partir de ello, las instituciones financieras redujeron el financiamiento no sólo a inversión en la industria de la construcción y el sector inmobiliario sino en el interbancario. Junto a la caída de las ganancias y ante peores perspectivas de la demanda se cancelaron planes para la inversión en inventarios, la ampliación de plantas, y la renovación de equipos. Así la crisis llegó al sector real de la economía.

c) El aumento de las tasas de interés a los créditos otorgados a estratos de la población no incorporados al proceso de acumulación capitalista no 
se pudo seguir pagando porque sus ingresos eran inestables o demasiado reducidos.

d) La titularización de las hipotecas imposibilitó su evaluación porque la misma dependía ya no del valor de la propiedad y de los procesos de urbanización que soportaban los diferenciales de precios entre las diversas viviendas, sino del comportamiento de los fondos dinerarios de corto plazo que garantizaban el valor de los créditos subprime y bastó la caída del valor de las hipotecas titularizadas para que diversas instituciones financieras empezaran a tener pérdidas significativas y pasivos cada vez mayores. Sólo en este momento las agencias evaluadoras de dichos fondos los degradaron como fondos de inversión seguros, generando con ello una ola de quiebras bancarias.

\section{LAS CRISIS FINANCIERAS RECIENTES Y LA NECESIDAD DE CONSTRUIR EXPLICACIONES ALTERNATIVAS RESPECTO DE LA ACTUAL CRISIS SISTÉMICA}

Aunque la internacionalización del capital que trajo la globalización financiera parecía ser la vía para que los países de menor crecimiento pudieran acercarse en términos de desarrollo a los países del primer mundo, lo acontecido fue el inicio de un largo periodo caracterizado por intervalos de diferente duración en los que se intercalan secuencias de estabilidad seguidas de una gran volatilidad e inestabilidad financieras. Uno de los momentos críticos de esa evolución fue la crisis financiera mexicana de 1994, una de las más severas de nuestra historia. ${ }^{21}$ A ésta siguió la argentina de 1995, después vino la de julio de 1997 cuando el bath tailandés se devaluó arrastrando consigo los sistemas financieros de Indonesia, Malasia, Corea (1977-78), Filipinas (1998). En ese mismo año sucumbiría Rusia. ${ }^{22}$ Posteriormente, Brasil tendría su turno sólo para dar paso a

21 Ésta llevaría a diversos actores internacionales - entre ellos el gobierno norteamericano, el FMI y los bancos centrales de los países industrializados- a diseńar un paquete de rescate financiero de 50000 millones de dólares y que fue utilizado en gran parte para amortizar valores públicos de corto plazo -tesobonos- por cerca de 40000 millones de dólares colocados principalmente entre inversionistas extranjeros y que debían amortizarse en 1995.

Hay que ańadir que en la década pasada las grandes crisis empezaron con la del Sistema Monetario Europeo de 1992-1993, y a las ya comentadas en el texto restaría agregar la del Fondo de Inversiones Long Term Capital Management en 1998, y la nueva crisis que en 2002 azotó a la economía argentina. 
la crisis turca de 1999 y a los programas de ajuste del 2001 relacionados con la crisis cambiaria en Argentina. En prácticamente todos estos casos, a diferencia de lo que había acontecido una década antes con los grandes desequilibrios en las finanzas públicas y el endeudamiento de los gobiernos, el endeudamiento se había producido del lado del sector privado financiero y no financiero, a lo que se sumaron fuertes déficits comerciales. Las salidas masivas de capitales en casi todos los casos hicieron insostenibles los regímenes de tipo de cambio fijos y precipitaron crisis cambiarias que al reducir la liquidez afectaron a los sistemas financieros y las economías regionales.

Estos fenómenos mostraron que la globalización, lejos de fortalecer a los mercados financieros, amplió los márgenes de volatilidad y evidenció que el estado de confianza podría deteriorarse rápidamente si como decía Keynes (1981), al referirse a los problemas económicos de su tiempo, se deja de lado la observación permanente de los mercados y de la psicología de los negocios. Situación favorecida por agentes de gran poder económico y financiero -agencias calificadoras, inversionistas institucionales o agencias reguladoras- que indujeron la realización de operaciones especulativas, las cuales potenciaron de forma desusada los grados de fragilidad e inestabilidad financiera como en su momento describió Minsky. ${ }^{23}$

\section{La crisis sistémica y los modelos explicativos sobre las crisis}

La naturaleza de la crisis sistémica ${ }^{24}$ por la que atraviesa la economía mundial y la habilidad del sector financiero para especular con la renta del suelo urbano dan pauta a reflexionar sobre algunas de las explicaciones convencionales respecto de las crisis pasadas y de la enorme crisis actual, así como a revisar si las políticas instrumentadas a partir de las mismas son pertinentes para encontrar una

23 Ideas y conceptos desarrollados en las obras previamente citadas de este gran economista.

24 Ésta es una crisis que afecta el funcionamiento del sistema capitalista como un todo, y expresa el desacoplamiento de las esferas real y financiera en una dinámica donde las finanzas giran en torno a la especulación y el crecimiento se basa, no en la producción y el comercio, sino en el endeudamiento. Por su parte las crisis financieras, por ejemplo bancarias, se producen como respuesta anticipada a potenciales dificultades financieras, y se manifiestan en corridas bancarias que, posteriormente, se traducen en fenómenos de iliquidez e insolvencia y bajo ciertas circunstancias pueden afectar a otros intermediarios financieros. En ese sentido, mientras una crisis sistémica incluye una disrupción violenta en el sistema financiero, una crisis financiera no necesariamente conlleva a una crisis de las proporciones de la primera. 
solución a la fuerte recesión que vive el planeta, o si bien son sólo marcos interpretativos para justificar el statu quo de la globalización en diversos momentos del tiempo y en tal caso, su utilidad reside en disfrazar las políticas económicas orientadas a resarcir la rentabilidad del capital para hacerlas ser más llevaderas a la mayoría de los habitantes de este planeta.

En un breve recuento de las medidas instrumentadas para paliar la crisis que está afectando a Estados Unidos tenemos lo siguiente: la Reserva Federal y las autoridades europeas, británica y japonesa inyectaron (y probablemente seguirán inyectando conforme sea necesario) enormes sumas de liquidez en los mercados monetarios para paliar lo que en un primer momento se pudo considerar un problema de liquidez. Posteriormente, se ha desarrollado una política de reducción de los tipos de interés y se ha dado la virtual congelación del mercado de papel comercial en Estados Unidos. Asimismo, se han desarrollado estrategias para ayudar a los titulares de hipotecas con dificultades de pago y se puso en marcha la política fiscal, con propuestas de aumento del gasto público, que han incrementado hasta niveles del 10\% del PIB su déficit fiscal. Políticas que se han implementado conforme han aparecido los síntomas de la propia crisis. Inyectar dinero al mercado financiero y rescatar a grandes bancos e inversores institucionales busca, por una parte, que no se cancele la capacidad del pago del sector financiero internacional pues de no hacerlo la magnitud de la crisis sería aún mayor. La reducción de las tasas de interés tiene por objetivo propiciar el crecimiento de la demanda y buscar que el precio de las viviendas no se desplome por efecto de un movimiento de péndulo que habría ocasionado un estancamiento en el sector construcción sin precedente desde la recesión de 1929. Al respecto cabe señalar que en Estados Unidos el sector construcción representa alrededor de una cuarta parte de la inversión fija bruta, por lo cual, una quiebra generalizada del sector inmobiliario traería como consecuencia su quiebra, una caída pronunciada en la formación bruta de capital dados los eslabonamientos productivos de ese sector con el resto de la economía.

El programa de apoyo a deudores hipotecarios tiene por objetivo restablecer la capacidad de pago de los consumidores, buscando con ello rescatar la mayor cantidad posible de recursos de las quiebras en el sector inmobiliario. El incremento del gasto público se dispone a controlar el nivel de desempleo para no generar una crisis mucho más profunda a nivel social. Baste considerar que éste fue de $6.8 \%$ en octubre del 2008 y durante 2010 se estimó en niveles cercanos al 10\%. ${ }^{25}$ Si comparamos las medidas que se están utilizando para paliar la actual crisis, consistentes con la problemática descrita en este trabajo, con los diagnósticos y las estrategias

25 Inegi. http://dgcnesyp.inegi.org.mx/cgi-win/bdiecoy.exe/575?s=est\&c=12953 [03/01/2010 04:38:04 p.m.] 
de política económica orientadas a su solución y prevención, anteriormente existentes, encontramos que su aplicación generaría una profundización de la misma.

Ello en tanto las crisis -o la crisis- en la economía convencional se perciben como "anormalidades extrañas", equiparables a simples fluctuaciones que se puede revertir ${ }^{26}$ ya que cambios ulteriores en el sistema de precios al modificar la oferta y la demanda restauran el equilibrio económico. ${ }^{27}$ En esos términos, los modelos explicativos respecto de las crisis económicas, financieras o cambiarias son resultados de las condiciones en que cada una de ellas se ha desarrollado. En los setenta y ochenta, y con el creciente endeudamiento público y los desequilibrios en las cuentas externas, se acuñó la descripción de las crisis tradicionales de balanza de pagos que llevaron a la implementación de severos programas de ajuste económico. Los años noventa vieron una combinación de desequilibrios externos, creciente endeudamiento externo, principalmente privado, a corto plazo y sistemas bancarios domésticos frágiles. ${ }^{28}$ La evolución descrita sirvió para definir las crisis gemelas, donde al colapso cambiario siguió de manera casi inmediata el colapso de los sistemas financieros, empezando por los bancos. ${ }^{29} \mathrm{El}$ interés por las condiciones en que se produjeron las diferentes crisis resultó en estudios orientados a entender su gestación -las causas- y construir marcos analíticos para el diseño de políticas que deberían permitir su prevención y solución. ${ }^{30}$ Mariano, et al, integran esos estudios en tres grandes grupos.

26 En la escuela neoclásica las crisis pueden verse como resultado de falta de disciplina del mercado o de fallas en la supervisión, pero no como un fenómeno inherente al propio modelo de producción capitalista.

27 Para el tema de crisis puede consultarse Hicks (1976); Kindleberger (1991); Fondo Monetario Internacional (FMI), (1998); Mishkin (2001). Además de una cantidad impresionante de trabajos sobre crisis ligadas a aspectos financieros. Por ejemplo: los trabajos de Diamond and Dybvig (1983); Díaz-Alejandro (1985); Calvo (1987); Bustelo (2000); Edwards (2000); Boorman and others (2000); Edison and others (2004); y, Ortiz (2002) entre otros.

28 Y ni qué decir de lo que va de la presente década en que se está viviendo la crisis financiera más profunda después de la de los años treinta del siglo pasado, y que rápidamente se convirtió en una crisis financiera internacional de magnitud insospechada que ha afectado a la economía mundial.

29 A esa tipología tendrá que añadirse una nueva clase de crisis que deberíamos llamar crisis de la innovación financiera y que, a pesar de compartir algunas características con crisis previas, cualitativamente tiene rasgos diferentes.

30 Prácticamente todos los estudios sobre crisis financieras concuerdan en que cuando se combina una crisis bancaria con una cambiaria los efectos sobre la economía real son mayores que cuando se presentan por separado. 
Los modelos de primera generación, que ubican como determinantes de las crisis déficits fiscales insostenibles frente a tipos de cambio fijos (Mariano, et. al, 2000). Los modelos de segunda generación en los que el detonante de las crisis es la naturaleza autorrealizada de las expectativas de los agentes económicos. Los modelos de tercera generación en los que la crisis en un país aumenta la probabilidad de contagio en otro u otros países a partir de las relaciones comerciales y financieras existentes entre grupos de países (Cuadro 4).

\section{Cuadro 4}

Modelos de Crisis Financieras

Modelos de $1^{\underline{a}}$ generación: con Modelos de $2^{\underline{a}}$ generación, con Modelos de $3^{\underline{a}}$ generación, con énfasis en los déficits fiscales énfasis en el comportamiento de las énfasis en cómo la liberalización cuentas de capitales financiera aumenta los problemas de riesgo moral $y$ lleva a crisis bancarias que después se convierten en cambiarias.

Metodología (Varía dependiendo de la tipología de la crisis)

Modelos logit y/o probit construidos para predecir crisis bancarias y crisis monetarias. El modelo estimado permite conocer la probabilidad de ocurrencia de una crisis dados los valores anticipados de las variables explicativas. Modelos econométricos para predecir la probabilidad de que produzcan crisis gemelas. El modelo de señales permite medir directamente la importancia, mediante un proceso binario, de cada candidato a variable explicativa.

\section{Evalúan el comportamiento de} las tasa de crecimiento del PIB, inflación, tasas de interés, déficit en la balanza de pagos, crédito interno, sobrevaluación del tipo de cambio y seguros de depósitos.

Krugman (1979). Las crisis se desarrollan como consecuencia de políticas económicas expansivas (fiscales y monetarias) que terminan revaluando el tipo de cambio y, con ello, se producen grandes déficits en la balanza de pagos
Ponen atención en el comportamiento de los movimientos de capitales y el impacto que las salidas de los mismos tienen en los tipos de cambio.
Obsffeld (1994) Krugman (1998). Un cambio en los fundamentos macroeconómicos derivados de variaciones abruptas del tipo de cambio conduce a la salida masiva de capitales que, tras la pérdida de reservas, precipita la crisis económica.
Enfoque de Signos o Alertas
Tempranas. Incluye muestras grandes y un amplio rango de indicadores: reservas internacionales, tipo de cambio real, crédito al sector público, inflación, balanza comercial, M2/ reservas internacionales, crecimiento del PIB y déficit fiscal.
Kaminsky y Reinhart (1998); Calvo y Reinhart (1996), Kamisky, et al (1998). La existencia de garantías implíititas favorece la toma de riesgos en los mercados cambiarios, con la subida de las tasas de interés internacionales y la consiguiente salida de capitales se precipitan la crisis cambiaria y la bancaria (crisis gemelas).

Fuente: Feldstein (2002); Rousseau and Sylla (2001); Sharma, Sunil (1999); Krugman (1979, 1998); Obstfeld (1988); Calvo and Reinhart (1996); Kaminsky and Reinhart (1998); Kaminsky and others (1998). 
En tanto las reformas económicas y financieras posteriores a los ochenta del siglo pasado tendrían que haber creado un ambiente macroeconómicamente más estable con la "construcción" de una base financiera más sólida, los modelos antes mencionados deberían haber servido para prevenir, o al menos enfrentar en mejores condiciones la enorme crisis financiera actual. Su dilema es que a pesar del gran esfuerzo cuantitativo y del trabajo analítico por establecer diagnósticos, secuenciación, variables a controlar y parámetros de comportamiento aceptables en la prevención de las crisis financiero-económicas, éstas se vienen presentando con mayor regularidad, con efectos más severos porque a las caídas en el producto resultante de las crisis anteriores se suman las pérdidas de bienestar de las nuevas crisis, de ahí que sus consecuencias económicas y sociales sean cada vez más devastadoras. Esto demuestra que la pretensión de que los resultados macroeconómicos pueden obtenerse mediante la simple agregación del comportamiento maximizador de un actor individual y racional que se mueve en mercados eficientes, mismo que se puede evaluar y predecir estadísticamente con métodos cuantitativos y econométricos cada vez más sofisticados, es insuficiente para entender el funcionamiento de la economía, la incertidumbre fundamental que la envuelve y las motivaciones que llevan a los agentes económicos a invertir especulativamente en la búsqueda de grandes ganancias. Fenómenos que afectan el funcionamiento no sólo del sistema financiero sino de la macroeconomía en su conjunto. De ahí que a pesar del alto grado de formalización de los métodos y los modelos para prevenir las crisis, su permanencia y regularidad siembran dudas respecto de sus resultados y predicciones. Por ello, y reconociendo que si bien es cierto son innegables los avances en el uso del herramental matemático en el campo económico y, particularmente, en el campo financiero, vale la pena tomar en cuenta a Toporovski cuando señala:

El formalismo está libremente asociado con la conversión del análisis económico en modelos matemáticos. Sin embargo, mientras la matemática tienen un lugar en la economía, ésta no puede sustituir el estudio acerca de cómo funcionan los mercados. Keynes correctamente criticó a Irving Fisher por confundir lo que una ecuación le decía que sucedería con lo que sucedería en el mundo real. No es suficiente tener una ecuación que relacione dos variables: es necesario tener la explicación de cómo esas variables se relacionan en la economía. Cuando tal relación incluye un supuesto de equilibrio, que por razones técnicas de determinación es necesario en los modelos financieros, el resultado es un supuesto de estabilidad, que puede no existir en el mundo real (2005:2).

La reflexión hecha hasta aquí refuerza nuestra idea de que la actual crisis sistémica representa retos importantes que deben ser acometidos con perspectivas económicas alternativas, no sólo para modificar el funcionamiento de los 
mercados financieros sino para sentar las bases sobre las cuales construir formas de interrelación económica entre países, diferentes a las emanadas de la más reciente etapa de la globalización financiera y que han mostrado ser devastadoras para la actividad económica y el bienestar de la población.

\section{CONCLUSIONES}

Los retos que plantea la enorme crisis sistémica que afecta a las finanzas internacionales y a la economía mundial, y cuyos riesgos en la forma de la temida deflación están lejos de desaparecer, abarcan el campo teórico y el práctico. En el primero se ubica de forma ineludible la necesidad de reconocer que con el herramental y las prescripciones de política económica de la teoría económica predominante -neoliberal- no sólo no se pudo detener la crisis desde sus primeras manifestaciones en el 2007 sino por el contrario, se incrementaron la incertidumbre y la inestabilidad que finalmente llevaron a una crisis de proporciones no vistas desde la gran crisis de 1929. En este sentido es urgente la revisión de las ideas, los modelos y los supuestos sobre los que se asentó el funcionamiento de la economía mundial por lo menos desde los años setenta del siglo pasado. Esto nos pone en el camino de recuperar ideas económicas muy desdeñadas -la incertidumbre fundamental, la renta de la tierra, el capital dinerario, la concentración y la centralización del capital, etcétera- y construir perspectivas económicas que integren elementos que únicamente se obtienen con la observación permanente del comportamiento de los mercados, y en especial por su importancia para el rumbo económico, de los mercados financieros. En tal sentido la vigencia del pensamiento Keynes es más que evidente, pues si bien no desarrolla una teoría de la crisis, sí explica el papel que juega la demanda efectiva en los comportamientos especulativos del mercado financiero y la incertidumbre que impactó la actividad en el sector real. Al mismo tiempo habría que retomar a Marx que sí desarrolla una teoría de la crisis sustentada en el propio devenir del funcionamiento del capital como capital productivo, dinerario y mercantil, donde la movilidad del capital se asocia al logro del máximo nivel de tasa de ganancia, lo que explica la salida del capital de la esfera productiva en busca de espacios de rentabilidad especulativos y en gran medida la naturaleza de la crisis actual. Retomar este pensamiento es ahora más relevante pues en la actual crisis financiera la propiedad de la tierra urbana se convirtió en un espacio de alta rentabilidad ligado a la especulación financiera.

En el terreno práctico la tarea no es menor. Se tendrían que definir nuevas reglas de operación del sistema financiero internacional, revisar la libre movilidad 
del capital y las políticas de tipos de cambio y de tasas de interés flexibles (consustanciales a la desregulación y la liberalización financieras) que tanto alentaron la especulación y destruyeron la coordinación y las bases de la planeación económica entre países. Esto pasa por reconocer que la supuesta autorregulación y la regulación prudencial no sirven para evitar que los animal spirits lleven, frente a expectativas de altas ganancias en operaciones financieras especulativas, a la toma de riesgos excesivos. Por lo tanto, tendrían que implementarse políticas públicas específicas en materia de innovaciones financieras, operaciones fuera de balance y apalancamiento de los propios intermediarios financieros a fin de asegurar grados de control suficientes para evitar la distorsión en los mercados financieros, y hacer compatible su funcionamiento con objetivos de crecimiento económico específicos.

De ahí que es imperioso desarrollar nuevos esfuerzos explicativos acerca de la gestación, la ocurrencia y la prevención de las crisis financiero-económicas. Una reflexión de esa naturaleza puede ayudar a diseñar políticas alternativas para construir las bases de un sistema financiero que apoye un crecimiento económico sostenible y más equitativo. Y ésta es una de las grandes lecciones que ha dejado la crisis del sector inmobiliario en Estados Unidos con sus efectos negativos no sólo en la construcción de casas habitación, y en otras formas de inversión como las obras públicas, sino fundamentalmente en el bienestar de la población y el estancamiento de la economía mundial. 
Ma. Guadalupe Huerta Moreno y Luis Kato Maldonado

\section{BIBLIOGRAFÍA}

Allen, Franklin y Anthony Santomero, What do Financial Intermediaries do? The Wharton School. University of Pennsylvania,1999.

Astarita, Rolando, "Material sobre crisis financiera II", Instituto de Estudios y Formación, Working Paper, Buenos Aires (2008).

Bank of International Settlements (BIS), Basel I, International Convergence of Capital Measurements and Capital Standards, Basel Committee on Bank Supervision. Basel Switzerland, 1988.

, A Revised Framework on International Convergence of Capital Measurement and Capital Standards, Basel Committee on Bank Supervision. Basel Switzerland, 2004.

Bellofiore, Ricardo and Joseph Halevi, "A Minsky Moment?, The Suprime Crisis and the "New" Capitalism", in International Economic Policy Institute, Working Papers 04, Canada, 2009, p. 4.

Bustelo, Pablo et al, Crisis financieras en economías emergentes: enseñanzas de Asia Oriental, Ediciones Cooperación al Desarrollo, Madrid, AECI, 2000.

Boorman, Jack and others, "Managing Financial Crises: the Experience in East Asia”, IMF Working Paper 00/107, Washington, 2000.

Calvo, Guillermo, "Balance of Payments in a Cash -in- Advance Economy", in Journal of Money, Credit and Banking, Vol.19, núm.1, 1987, pp. 19-32.

Calvo, Sara and Graciela Reinhart, "Capital Flows to Latin America: Is There Evidence of Contagion Effects?», en Guillermo A. Calvo, Morris Goldstein y Eduard Hochreiter (eds.), Private Capital Flows to Emerging Markets, Washington, D.c., Institute for International Economics, 1996.

Chihiro Shimizu and Tsutomu Watanabe, "Housing Market Fluctuation Factors in Japan and us", in Financial Review, num. 95, Policy Research Institute, Japan, Ministry of Finance, 2009, p. 1.

Correa, Eugenia, "Inversionistas institucionales en un mercado financiero global”, en Guadalupe Mántey y Noemí Levy (Coords). De la desregulación financiera a la crisis cambiaria: experiencias en América Latina y el sudeste asiático, México, UnAm, enep-Acatlán-DGAPA, 2000, p. 103.

Clavijo, Sergio, Crisis financieras, regulación y supervisión: algunas lecciones para economias emergentes, mimeo, 2001.

Cox Wendel, "Root Causes of the Financial Crisis: New Geography” (2009). http://www.newgeography.com/content/00369-root-causes-financial-crisisa-primer [28/12/2009 09:02:16 p.m.

Daniel Titelman, Esteban Pérez-Caldentey y Ramón Pineda, “¿Cómo algo tan pequeño terminó siendo algo tan grande? Crisis financiera, mecanismos de 
contagio y efectos en América Latina”, en Revista CEPAL, 198, Santiago de Chile (2009).

Demirgüc-Kunt, Asli and others, Regulations, Market Structure, Institutions, and the Cost of Financial Intermediatio, NBER, Working Papers Series, num. 9890, 2003.

Diamond Douglas, W. and Dybvig, P.H, "Bank Runs, Deposit Insurance, and Liquidity”, Journal of Political Economy, 91 (June), 1983, pp. 401-19.

Díaz-Alejandro, Carlos, "Good-bye Financial Repression, Hello Financial Crash". Journal of Development Economics, 1985, pp. 19:1-24.

Duménil, Gérard y Dominique Lévy, "Neoliberal Dynamics, Imperial Dynamics", EconomiX, PSE: Paris (2003). Available en http://www.jourdan. ens.fr/levy/dle2003f.pdf. [último acceso en 9 de septiembre de 2010].

Edison, Hali, and others, "Capital Account Liberalization and Economic Performance: Survey and Synthesis", IMF Staff Papers, Vol. 51, num. 2, 2004, pp. 220-56;

Edwards, Sebastian, Capital Mobility and Economic Performance: Are Emerging Economies Different?, University of California, Los Angeles- NBER, 2000.

Eichengreen, Barry and Micheal Bordo, "Crises Now and Then: What Lessons From The Last Era of Financial Globalization?”, Working Paper 8717, NBRE, Cambridge, Massachusetts, 2002.

, Qué hacer con las crisis financieras. México, FCE, 2009.

Feldstein, Martin, "Economic and Financial Crises in Emerging Market Economies: Overview of Prevention and Management", Working Paper 8837. NBER, Cambridge, 2002. Disponible en: http://www.nber.org/papers/ w8837... Consultado el 7 de junio de 2009.

Fondo Monetario Internacional (FMI), "World Economic Outlook. Financial Crises: Causes and Indicators”, Washington, D.C, 1998.

Freixas, Xavier y J. Charles, Rochet, Economía Bancaria. Antoni Bosch, España, 1997.

Gontijo Claudio y de Oliveira Augusto, Subprime: Los 100 dias que abalaram o capital finaceiro mundial e os efeitos da crise sobre o Brasil, Belo Horizonte. coRECON MG Y ASSEMG (2009).

Hicks, John. R., Valor y capital, México, FCE, 1976.

Hiernaux-Nicolas, Daniel, "Hacia una geografía de la globalización” en Ma. A. Correa y R. Gutiérrez (Coord.), "Tendencias de la globalización en el nuevo milenio”, México, UAM-X, 2002.

Gorton, Gary and Richard Rosen, "Banks and Derivatives", nber Working Paper Series, num. 5100, Cambridge Ma. 02138, 1995.

Huerta, Ma. Guadalupe, La crisis financiera de la innovación y la reconstrucción de las politicas financieras para el desarrollo, ponencia presentada en el 
"Seminario Internacional Estructura Financiera y Desarrollo Económico. Teorías del crecimiento y el nuevo patrón de acumulación en países en desarrollo". Realizado los días 31 de agosto y $1^{\circ}$. de septiembre de 2009 en Ciudad Universitaria, México, D.F., 2009.

Kaminsky, Graciela and Carmen Reinhart, "The Twin Crises: The Causes of Banking and Balance of Payments Problems", American Economic Review 89, 1998, pp. 473-500.

and others, "Leading Indicators of Currency Crises". IMF Staff Papers, Vol. 45, 1998, pp. 11-43.

Keynes, John Maynard, Teoría general de la ocupación, el interés y el dinero, México, FCE, 198, p. 145.

Kindleberger, Charles, Manias, pánicos y cracks. Historia de las crisis financieras, Barcelona, Ariel, Sociedad Económica, 1991.

Krugman, Paul, "A Model of Balance of Payments Crises". Journal of Money, Credit and Banking, 11(3), 1979, pp. 311-25.

,"What happened to Asia", 1998, disponible en http://web.mit.edu/krugman/www/DISINTER.html..., consultado el 3 de febrero de 2007.

Levy, Noemí, "Innovación financiera y crecimiento económico", en Ola Financiera, núm. 5, México, enero-abril, 2010.

Mariano, Roberto S. et al, Models of Economic and Financial Crises, 2000, en http://www.luc.edu/orgs/meea/volume2/ozmucur1,pdf..., consultado el 8 de febrero de 2008.

Marx, Karl, El Capital, T. III, vol. 8, cap. XLVI, Siglo xxI, 1981.

Minsky, Hyman, Can it Happen Again. Essays on Instability and Finance, New York, M. E. Sharpe, 1982.

, Stabilizing and Unstable Economy, New Haven, C: Yale University Press, 1986.

Mishkin, Frederic, "Financial Policies and the Prevention of Financial Crises in Emerging Market Countries", National Bureau of Economic Research (NBER), 2001, en http//www.nber.org., p. 2. Consultado el 13 de marzo de 2008.

Ortiz, Guillermo, Recent Emerging Market. Crises: What Have we Learned, Peter Jacobsson Foundation, Basel, Switzerland (2002).

Obstfeld, Maurice, "The Global Capital Market: Benefactor or Menace", Journal of Economic Perspectives, 12(4), 1988, pp. 9-30.

Paul van den Noord, Are House Prices Nearing a Peak? A Probit analysis for 17 OECD Countries, OCDE, Economics Department Working Papers, num. 488 (2006).

Puyana, Jaime, "Liberalización de los flujos de capital y su efecto en la economía mundial", en E. Correa, et al, Consecuencias financieras de la globalización, México, Ed. M. A. Porrúa-IIE, unAM, 2005, pp. 23-53. 
Rousseau, Peter and Richard Sylla, "Financial Systems, Economic Growth, and Globalization”, Working Paper 8323, NBER, Cambridge, Massachusetts, 2001.

Rozo, Carlos, "La globalización: propuesta y paradojas. La experiencia de los países industriales", Investigación Económica, 234, 2000, p. 76.

Sharma, Sunil, "El desafío de predecir las crisis económicas", Finanzas y Desarrollo, 1999, pp. 40-42.

Schwarcz, Steven L, Systemic Risk. Duke Law School Legal Studies Paper, num. 163; Georgetown Law Journal, vol. 97, num. 1 (2008), disponible en http:// ssrn.com/abstract=1008326... consultado el 7 de junio de 2008.

Toporovski, Jean, Theories of Financial Disturbance. An examination of Critical Theories of Finance from Adam Smith to the Present Day, UK, Edward Elgar, Cheltenham, 2005, p. 2.

Williamson, John, "What Washington Means by Policy Reform", in J. Williamson (Ed.), Latin American Adjustment: How Much has Happened?, Washington, D.C., Institute for International Economics, 1990. 
